\title{
A STUDY TO ASSESS THE SELF-ESTEEM AND ATTITUDE TOWARDS NURSING PROFESSION AMONG FINAL YEAR NURSING STUDENTS STUDYING IN D. Y. PATIL COLLEGE OF NURSING, KOLHAPUR
}

\author{
Mr. Praveen L. Subravgoudar*
}

*Associate Professor, D. Y. Patil College of Nursing, Kadamwadi, Kolhapur, Maharashtra, India. DOI: http://doi.org/10.47211/idcij.2020.v07iws02.007

\section{ABSTRACT}

Choosing a profession is a complex process affected by many factors varying from one country to another and from one culture to another. In addition to the properties of the profession and individual characteristics of the person, environmental conditions, political, economic, legal and systematic characteristics, luck, norms, and social values and attitudes affect one's choice of profession. In choosing a profession, if a person is to adapt to the profession and to maintain a productive working life, he/she should have a positive opinion of and attitude towards the profession. Having a positive opinion of and attitude towards the profession plays an important role not only in fulfilling individual success but also in the development of the profession. Nursing schools need students who have qualifications appropriate to the nursing profession and display a positive attitude towards it. Therefore, to develop the nursing profession, nursing schools should educate students so that the students can have qualifications appropriate to the nursing profession and display a positive attitude towards it. Nursing students face many difficulties during their education process. A streamlined course consisting of a unified and comprehensive syllabus replacing different levels of courses, such as a diploma course, including Auxiliary Nurse Midwife (ANM) and General Nursing and Midwifery (GNM), and a BSc in nursing, should be introduced. Self-esteem is a person's Personal judgement of his or her own worth, based on how well behaviour matches up with self-ideal. The frequency with which a person attains goals directly influences feelings of competency (High self-esteem) or inferiority (low-self-esteem) self-esteem comes from two primary sources: the self and others. It is first function of being loved and gaining the respect of there. Self-esteem is lowered when love is lost when one fails to receive approval from others. Attitude is a psychological construct, a mental and emotional entity that inheres in, or characterizes a person. They are complex and are an acquired state through experiences. It is an individual's predisposed state of mind regarding a value and it is precipitated through a responsive expression towards a person, place, thing, or event (the attitude object) which in turn influences the individual's thought and action. Prominent psychologist Gordon Allport described this latent psychological construct as "the most distinctive and indispensable concept in contemporary social psychology. Attitude can be formed from a person's past and present. Key topics in the study of attitudes include attitude strength, attitude change, consumer behaviour, and attitude-behaviour relationships.relationships.

Key Words: Self-esteem, psychological needs, nursing profession.

\section{ABOUT AUTHOR:}

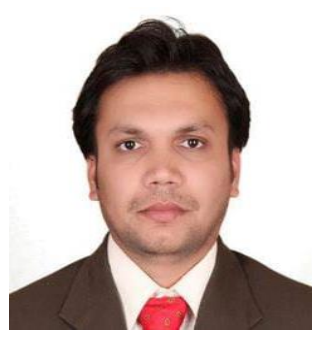

Author, Mr. Praveen L. Subravgoudar is working as Associate Professor at D. Y. Patil College of Nursing, Kadamwadi, Kolhapur, Maharashtra, India. 


\section{NEED FOR THE STUDY}

Self-esteem is one of our basic Psychological needs. The importance of self-esteem can be considered from several perspectives. It is important to normal psychological development. To adequately cope with the challenges of growing and developing, person need to believe that they have the capacity to achieve what they need and want to and that they are deserving of happiness and joy in life. The effect of self-esteem may also be seen in carrier planning and decision making.

Registering for advanced placement classes or applying to a highly competitive college may also challenge the self-esteem of an individual. It has also been suggested that high self-esteem impart to person immunity to the downturns in the roller coaster of life.

A study conducted by HOLLY (1987) to measure student self-esteem level for academic success. He acknowledged that a certain level of self-esteem is required in order for a student to achieve academic success.

A study conducted by the KAPLAN (1975). He found in a long-term study of $3000,7^{\text {th }}$ grade students that lower level of self - esteem were most likely to adopt deviant behavior patterns. Low self-esteem becomes a tremendous source of anger and hostility which frequently results in violence.

The higher our self-esteem, the more open, honest, and appropriate our communications are likely to be , because we believe our thoughts have value and therefore we welcome rather than fear the clarity. The lower our self-esteem, the more Moddy, evasive and in appropriate our communication are likely to be, because of uncertainty about our own thoughts and feeling and anxiety about the listen response. The development of a strong sense of self-esteem is important to withstand the family stresses, social pressures, and temptations of deviance encountered at any age of life. Low self-esteem is linked to poor health and deviant social behaviours such as smoking, substance abuse, poor academic achievement, depression, suicide, and pregnancy. Conversely, high self-esteem is linked to increased performance, improved health, and productive behaviour. Such evidence suggests higher levels of self-esteem may lead to more success in life and greater motivation for health maintenance and behaviors. ${ }^{7}$

Low self-esteem either causes or contributes to nervousness, anxiety, defensiveness, and ultimately alcohol and drug abuse. Psychology factor (Sagan, 1990), including self-esteem have a greater impact on health than drugs, new medical procedures and high-tech equipment of modern medicine. This healthiest person today is one with self-esteem and a sense of personal control. Those who feel good about themselves are less susceptible to not only psychosomatic illness but also more resistant to disabilities like cancer. ${ }^{9}$

Understanding attitudes, competencies, and the intended work location among nursing students may help inform policy as well as helping in the design of interventions that would encourage nurses to choose to work in rural areas where they are most needed.

\section{METHODS}

A Non-experimental descriptive correlation research design was used for this study. Hundred final year nursing students studying in D. Y. Patil College of nursing were selected by using Non probability convenient sampling technique and the data was collected by using Modified self-esteem scale \& Attitude Scale.

\section{RESULT}

The study finding of the self-esteem score of final year nursing student revealed that $44 \%$ had High level of self-esteem, $54 \%$ had Optimum level of self-esteem, whereas majority $2 \%$ had Medium level of self-esteem as well as $96 \%$ had positive attitude $\& 4 \%$ had negative attitude towards nursing profession. The Result of Correlation indicates $(r=0.63)$ moderately positive correlation between Self Esteem \& Attitude Score towards nursing profession among final year nursing students. The finding also shows that there was association between the Self-esteem scores with Gender of final year nursing students. 


\section{ARTICLES}

Section I: Findings related to selected demographic variables of the people

Table 1: Frequency and percentage distribution of people according to their selected demographic variables $n=100$

\begin{tabular}{|c|c|c|c|}
\hline Sr. No & Demographic variables & Frequency(f) & Percentage\% \\
\hline 1. & $\begin{array}{c}\text { Age } \\
\text { 20-21 year } \\
\text { 22-23 year } \\
\text { 23-24 year } \\
25 \text { \& Above }\end{array}$ & $\begin{array}{c}56 \\
29 \\
6 \\
9\end{array}$ & $\begin{array}{c}56 \% \\
29 \% \\
6 \% \\
9 \%\end{array}$ \\
\hline 2. & $\begin{array}{l}\text { Gender } \\
\text { Male } \\
\text { Female }\end{array}$ & $\begin{array}{l}39 \\
61 \\
\end{array}$ & $\begin{array}{l}39 \% \\
61 \% \\
\end{array}$ \\
\hline 3. & $\begin{array}{l}\text { Religion } \\
\text { Hindu } \\
\text { Muslim } \\
\text { Christian } \\
\text { Others }\end{array}$ & $\begin{array}{c}51 \\
9 \\
37 \\
3\end{array}$ & $\begin{array}{c}51 \% \\
9 \% \\
37 \% \\
3 \%\end{array}$ \\
\hline 4. & $\begin{array}{l}\text { Residence } \\
\text { Urban } \\
\text { Rural }\end{array}$ & $\begin{array}{l}71 \\
29\end{array}$ & $\begin{array}{l}71 \% \\
29 \%\end{array}$ \\
\hline 5. & $\begin{array}{c}\text { Family background } \\
\text { Yes } \\
\text { No }\end{array}$ & $\begin{array}{l}52 \\
48\end{array}$ & $\begin{array}{l}52 \% \\
48 \% \\
\end{array}$ \\
\hline 6. & $\begin{array}{c}\text { Course } \\
\text { Basic B.sc (N) } \\
\text { P.B.B.Sc (N) } \\
\text { GNM }\end{array}$ & $\begin{array}{l}46 \\
25 \\
29\end{array}$ & $\begin{array}{l}46 \% \\
25 \% \\
29 \%\end{array}$ \\
\hline
\end{tabular}

Table 2: Level of Self-Esteem Score of final year nursing students towards nursing profession.

$n=100$

\begin{tabular}{cccc}
\hline $\begin{array}{c}\text { Level of Self } \\
\text { Esteem }\end{array}$ & $\begin{array}{c}\text { Range of } \\
\text { score }\end{array}$ & Frequency & Percentage \\
\hline High & $82-105$ & 44 & $44 \%$ \\
Optimum & $54-81$ & 54 & $54 \%$ \\
Medium & $27-53$ & 2 & $2 \%$ \\
Low & $0-26$ & 0 & 0
\end{tabular}

Data in Table 2 show that $44 \%$ of the people had high self-esteem, $54 \%$ had an optimum, $2 \%$ had medium and $0 \%$ had a Low level of Self Esteem towards Nursing Profession.

Self Esteem Score

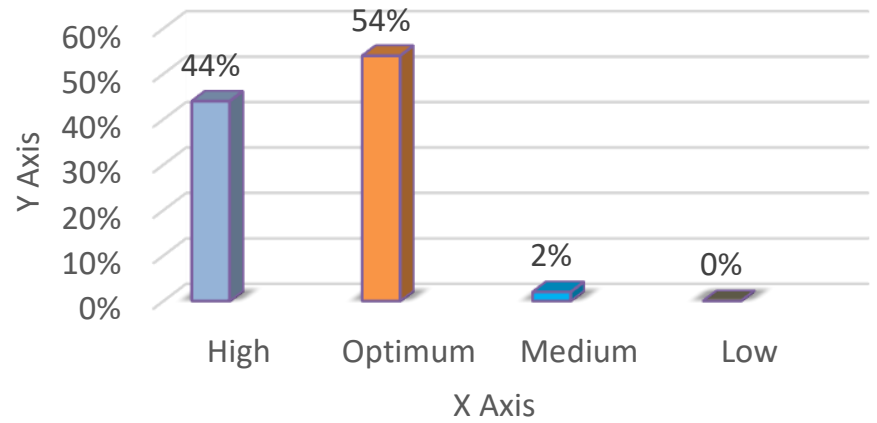

Graph 1: The Bar Diagram Showing Percentage Distribution of Self-Esteem Score of final year nursing students towards nursing profession. 
Table 2: Frequency and percentage distribution of the final year nursing students according to the Attitude score.

$\mathbf{N}=100$

\begin{tabular}{ccc}
\hline Attitude & Frequency & Percentage \\
\hline Positive & 96 & $96 \%$ \\
Negative & 4 & $4 \%$
\end{tabular}

Data in Table 2 show that $96 \%$ of the adolescents had positive, $4 \%$ had a negative attitude towards Nursing Profession.

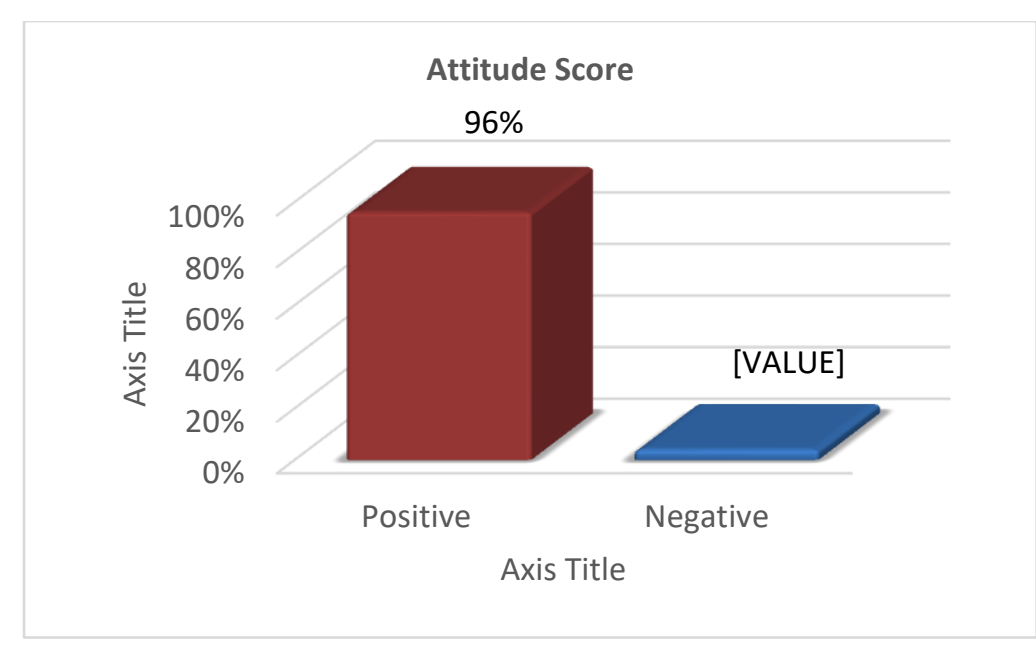

Graph 2: The Bar Diagram Showing Percentage Distribution of Attitude Score of final year nursing students towards nursing profession.

DISCUSSION

The major findings of the study are -

1. Findings related to selected demographic variables of nursing students.

2. Findings related the Self-Esteem towards Nursing Profession among final year nursing students.

3. Findings related the attitude towards Nursing Profession among final year nursing students.

4. Correlation between self-esteem and attitude Nursing Profession among final year nursing students.

1. Findings related to selected demographic variables of nursing students-

In the present study, a sample size of 100 students in nursing college Kolhapur was taken. The data presented in table no. 1 indicates that maximum 56 (56\%) of samples belonged to the age group of 22-23 years, 6(6\%) of samples belongs to age group of 23-24 years. 9(9\%) of samples belonged to the age group of 25 \&above. In terms of gender maximum number of samples 61 (61\%) were female and $39 \%$ were male. In terms of religion maximum of samples 51(51\%) belonged to Hindu religion, 37(37\%) belonged to Muslim religion minimum 3 (3\%) were Christian religion $9(9 \%)$ belonged to other religion in terms of residence maximum number of sample in the urban area $71(71 \%), 29(29 \%)$ sample are from rural. In terms of family background maximum number of samples 52(52\%) \& minimum number having family background is $48(48 \%)$. In terms of course of sample Basic B.Sc. nursing are 46(46\%) P.B.B.Sc nursing are 25(25\%) and GNM are 29(29\%).

2. Findings related to the Self-Esteem towards Nursing Profession among final year nursing students-

The finding shows that $44 \%$ of the nursing students had high self-esteem, $54 \%$ had an optimum, $2 \%$ had medium and $0 \%$ had a Low level of Self Esteem towards Nursing Profession.

A study supporting with similar findings was undertaken, to assess the effect of parent-child interaction on self-esteem as mediated by emotional support and self-perception among undergraduate nursing students in Thailand. Results revealed that the students reported relatively high self-esteem. Self-esteem was powerfully predicted from emotional support and moderately predicted from self-perception. These variables account for $37 \%$ of the variance in self-esteem.

The study findings were contradictory with study, which adopted a descriptive research design, where simple random sampling was used to collect data from 35 B.Sc. (Nursing) students from a selected nursing college in Bangalore. Majority i.e. 24(68.6\%) of the subjects reported to have normal level of self-esteem; while, 
$11(31.4 \%)$ of them have low self-esteem. None of the subjects demonstrated to have high self-esteem. The results of the study can be useful to nursing educators whose efforts are focused on promoting professional identity development of future nurses.

3. Findings related the attitude towards Nursing Profession among final year nursing students-

The finding shows that $96 \%$ of the adolescents had positive attitude, $4 \%$ had a negative attitude towards Nursing Profession.

A study supporting with similar findings was undertaken, to assess the attitudes of students towards the nursing profession in Sultan Qaboos University. The total sample of 377 students (male = 130; female = 247) were selected from the different colleges of Sultan Qaboos University by using the convenience sampling. Findings of study disclose that both the male and female students in all the academic years and colleges had a positive attitude toward the nursing profession. The study concluded that the serious efforts should be made to promote the nursing profession and so guard that it remains positively regarded by all concerned.

The study findings were contradictory with study which was conducted to assess the attitude of nursing students towards their profession in Andhra Pradesh, India. The total 437 samples were selected for the study by using a simple random sampling technique. The study results divulge that there was a significant difference between male and female students in the total attitude (t value $2.24^{*}$ ). The study concluded that the college management has to provide a good infrastructure and institution facilities to the student teachers, if all the facilities are good, automatically the attitude towards the nursing profession will be favourable.

4. Findings related to correlation between self-esteem and attitude among final year nursing students-

The study rresult of Correlation indicates $(r=0.63)$ moderately positive correlation between Self-Esteem \& Attitude Score towards nursing profession among final year nursing students. A study supporting with similar findings was undertaken, to investigate the relationship between middle school students' self-esteem and their perceived parental attitudes. The results indicate that students mostly perceive their parents' attitudes as democratic. Moreover, it was observed, that students had high self-esteem. As the democratic attitude, which is one of the sub-dimensions of parental attitudes, increases, a student's self-esteem also increases. However, when the parents' protective demanding and authoritarian attitudes increase, a student's self-esteem decreases.

5. Findings related to association between the Self-esteem scores with selected demographic variables among final year nursing students-

There was association between the Self-esteem scores with Gender of final year nursing students.

A study supporting with similar findings was undertaken, to assess the effect of parent-child interaction on self-esteem as mediated by emotional support and self-perception among undergraduate nursing students in Thailand. Results revealed that the students reported relatively high self-esteem. Apath model demonstrated the positive effect to parent-child interaction on emotional support and self-perception, and the positive effect so emotional support and self-perception on self-esteem.

6. Findings related to association between the Attitude scores with selected demographic variables among final year nursing students-

There was association between the Attitude scores with Religion \& Family Background of Final year nursing students towards Nursing Profession. A study supporting with similar findings was undertaken, to assess the attitude so students towards the nursing profession in Sultan Qaboos University. Findings of study disclose that both the male and female students in all the academic years and colleges had a positive attitude toward the nursing profession.

\section{CONCLUSION}

The present study, descriptive in nature was undertaken A descriptive study to identify the Self-Esteem \& Attitude towards Nursing Profession among final year nursing students studying in D. Y. Patil college of nursing, Kolhapur"

The study aimed at accomplishing the following objectives.

1. To assess the self-esteem \& Attitude towards nursing profession among final year nursing students studying in D. Y. Patil college of nursing, Kolhapur. 
2. To find out the association between the self-esteem and attitude scores on towards nursing profession among final year nursing students studying in D. Y. Patil college of nursing, Kolhapur.

Based on the findings of the study the following conclusions were drawn.

1. Overall self-esteem was Optimum

2. Over all attitude was positive

3. The study revealed association between self-esteem \&attitude scores and selected demographic variables.

\section{IMPLICATIONS OF THE STUDY}

The findings of the study have implications for the nursing profession. The implications have been written under the following headings-nursing practice, nursing administration, nursing education, nursing research and general education in schools and colleges.

\section{Nursing Practice}

1. It can be included in the health educational programme, which should be carried out in colleges and in community.

2. Teaching parents to provide children with a secure and mentally healthy environment to improve selfesteem \& attitude towards nursing profession.

\section{Nursing Education}

1. Nursing curriculum is responsible for preparing future nurses with emphasis on curative, preventive and promotive health practices.

2. Nurse educators should give more importance to professional development as they are future nurses and need to have adequate knowledge \& Skills in dealing with health sector.

3. Need to conduct in-service education for nurses and health workers.

\section{Nursing Administration}

Nurse administrators in the hospitals, in the community can organize in-service education for nurses and health awareness camps for the community regarding nursing profession.

1. Adequate information materials regarding Nursing profession made available to all final year nursing students, health personnel and to the public.

\section{Nursing Research}

1. The descriptive survey provides baseline for conducting other research studies.

2. The study will be a motivation for budding researchers to conduct similar studies on a large scale.

3. The study will be a reference for research scholars.

\section{General Education in Schools and Colleges}

Schools and colleges may include Seminars regarding awareness of nursing profession.

\section{LIMITATIONS}

No broad generalization could be made due to the small sample size and limited area of setting.

\section{RECOMMENDATIONS}

Based on the findings of the study, the major implication for the nurses was that this study does provide information to the people to increase their knowledge. The following recommendations were made.

1. Similar study may be undertaken with a larger sample to have a better generalization.

2. The same study can be conducted with an experimental research approach having a control group.

\section{INTERPRETATIONS \& CONCLUSIONS}

The finding reveals that most of the Final year nursing students had (96\%) positive attitude \& $54 \%$ had optimum level of self-esteem towards nursing profession. The finding shows that there was association between the self-esteem scores with gender of final year nursing students studying in D. Y. Patil College of Nursing, Kolhapur. 


\section{ARTICLES}

\section{REFERENCES}

1. Allport, Gordon. (1935). "Attitudes," in A Handbook of Social Psychology, ed. C. Murchison. Worcester, MA: Clark University Press, 789-844.1

2. Devi Ashalata. International Journal of Nursing Education 2013; 5(1):20-5.

3. Elizabeth A. Minton, Lynn R. Khale (2014). Belief Systems, Religion, and Behavioral Economics. New York: Business Expert Press LLC. ISBN 978-1-60649-704-3.

4. https://books.google.co.in/books?id=K4m_DQAAQBAJ\&pg=PT176\&redir_esc=y\#v=onepage\&q\&f=fals

5. Indian Nursing Council, Annual report for the year 2014-2015. New Delhi: Indian Nursing Council; 2015.

6. Lakhveer Kaur, Kanika and Ajesh Kumar. Assess the attitude of nursing students towards nursing profession. International Journal of Applied Research 2016; 2(6): 738-741

7. Lynn R. Kahle, Pierre Valette-Florence (2012). Marketplace Lifestyles in an Age of Social Media. New York: M.E. Sharpe, Inc. ISBN 978-0-7656-2561-8.

8. Poreddi V, Ramachandra, Konduru R, Math SB. Assessing the attitudes and perceptions towards nursing profession among nursing students. Nurs J India. 2012 Feb; 103(1):6-8.

9. Richard M. Perloff, The Dynamics of Persuasion: Communication and Attitudes in the Twenty-First Century, Routledge, 2016.

10. Zodpey S, Batra B, Negandhi H, Sharma K, Tiwari R. The 5-country situational analysis "health professional education for a new century". New Delhi: Public Health Foundation of India; 2013. 